\title{
Determination of HER-2/neu gene Status by Chromogenic in Situ Hybridisation Assay on Borderline (2+) Immunohistochemistry Cases in Patients with Invasive Breast Carcinoma: An Experimental Study on Preserved Tissue
}

\author{
Khanam KF, Choudhury T, Banu SG, Islam S \\ Bangabandhu Sheikh Mujib Medical University, Dhaka, Bangladesh \\ e-mail: kazifarzana1983@gmail.com
}

\begin{abstract}
HER-2 (also known as HER-2/neu) is a member of the epidermal growth factor (EGF) receptor family. The amplification of oncogene HER-2 is presented in 20 to $30 \%$ of breast cancers and results in an increase of the protein expression. HER-2 over expression has also been shown to correlate with poor prognosis. It is associated with poorly differentiated high grade tumors with lymph node involvement, greater risk of recurrence and relative resistance to some types of chemotherapy. The receptor is however a target for treatment with anti HER-2 antibody trastuzumab (Herceptin). Immunohistochemistry analysis for HER 2 scoring is subjective, requires trained personnel and expertise. One of the main concerns with IHC is that there is evidence of significant inter-observer variation in the assessment of staining, which can lead to misclassification of HER2 status. Chromogenic in situ hybridisation (CISH) testing is sensitive and specific in detecting HER2/neu gene amplification. Direct evaluation of gene amplification using CISH assay is a reliable method for routine diagnostic evaluation of HER2/neu status in breast cancer patients, especially in specimens showing 2+ IHC score. This observational experimental study was carried out in the Department of Pathology, Bangabandhu Sheikh Mujib Medical University (BSMMU), Dhaka, during the period of July 2014 to June 2015, The aim of this study was to assess HER-2 expression accurately in equivocal immunohistochemistry (2+) invasive breast cancer cases by Chromogenic in situ hybridisation and to associate the findings of CISH assay with the histologic prognostic and predictive factors (eg: tumor size, regional lymph node metastases, tumor grade and type. A total of 20 archival paraffin tissue blocks and IHC slides with IHC score 2+ for HER-2 were included in this study. All the slides were reviewed. CISH assay was done on section from archival paraffin block.CISH assay showed amplification of the HER-2 neu gene in 30\% of cases. Majority (60\%) was nonamplified. In two cases the results were unsatisfactory for interpretation. The differences were not statistically significant $(p>0.05)$ among three groups (amplified, nonamplified and unsatisfactory) regarding the baseline characteristics (age and sex) with CISH. All the results of CISH assay in association with tumor size, tumor grade and lymphnode metastasis were not statistically significant. HER-2 / neu status is the one of the most important prognostic and predictive factor. It is a target for treatment with anti HER-2 antibody trastuzumab (Herceptin). Detection of HER-2/ neu status by IHC may sometimes be difficult and inaccurate, specially in IHC score $2+$ cases. Based on the findings of the study, CISH can be considered as a useful, simple and reproducible method for detecting HER-2/ neu gene amplification in cases with borderline (2+) immunohistochemistry score and patients may be benefited from Trastuzumab therapy.
\end{abstract}

Keywords: HER-2/neu gene; Hybridisation assay, Invasive breast carcinoma

\section{Introduction}

Breast cancer is the second most common cancer in the world and, the most frequent cancer among women. According to the International Agency for Research on Cancer GLOBOCAN 2012, 1.67 million new breast cancer cases were diagnosed in 2012 (25\% of 
all cancers). The world wide incidence of breast carcinoma is 43.3 per 100,000 women and its incidence in Asia is 29.1 per 100, 000. ${ }^{1}$

The heterogenous disease group of breast cancers and its molecular subtypes has been characterized by many recurrent genetic abnormalities such as unbalanced chromosomal rearrangements, deletions and gene amplifications. ${ }^{2}$

There are both prognostic and predictive indicators for breast cancer. These are age at diagnosis, regional lymph node metastasis, tumour size, histologic subtype, histologic grade, estrogen and progesteron receptors, HER-2/neu status, lymphovascular invasion and proliferative rate etc. ${ }^{3}$ Current management of patients of carcinoma breast depends on the pathology and status of prognostic markers ER, PR, HER-2/neu etc. ${ }^{4}$

Among these factors, HER-2 (also known as HER-2/neu) is a member of the epidermal growth factor (EGF) receptor family which consists of four members: HER-1 (erbB1), HER-2 (erbB2), HER-3 (erbB3) and HER-4 (erbB4). HER-2 gene is located on chromosome 17q12 and encodes a $185-\mathrm{KDa}$ protein product which is a transmembrane receptor protein with tyrosine kinase activity. ${ }^{5}$ The biology of the HER-2 receptor is complex and it is involved in both cell differentiation and proliferation. The ampli-fication of oncogene HER-2 is presented in $20 \%$ to $30 \%$ of breast cancers and results in an increase of the protein expression. ${ }^{6}$ HER-2 over expression has also been shown to correlate with poor prognosis. It is associated with poorly differentiated high grade tumors, lymph node involvement, greater risk of recurrence and relative resistance to some types of chemotherapy. ${ }^{7}$ These result in a decreased survival from breast cancer. ${ }^{8}$ The receptor is a target for treatment with anti HER-2 antibody trastuzumab (Herceptin). ${ }^{9}$

Trastuzumab is a recombinant humanized monoclonal antibody that specifically targets the HER-2 receptors. ${ }^{10}$ Adjuvant trastuzumab reduces the risk of recurrence and mortality by about one half and one third respectively in patients with early stage breast cancer. ${ }^{11}$ The benefit of trastuzumab in HER-2/neu positive breast cancers has been well documented as noted by prolonged survival. ${ }^{12}$ But this therapy is effective only if the detection of HER-2/neu status is accurate.

There are several methods available to detect the HER-2/neu status like Immunohistochemistry (IHC), Fluorescence-in-situ hybridisation (FISH), Silver-enhanced in situ hybridisation (SISH), Chromogenic in situ hybridisation (CISH) and Polymerase Chain Reaction (PCR). ${ }^{13}$

IHC analysis for HER 2 is simple to perform, convenient to operate, easy to preserve the slides, relatively less expensive test and requires use of a familiar light microscope. ${ }^{14}$ But it is affected by several variables including tissue fixation method, reagent, assay protocol, antibody sensitivity and specificity and the scoring system. ${ }^{15}$ The scoring is subjective, requires trained personnel and expertise. One of the main concerns with IHC is that there is evidence of significant inter-observer variation in the assessment of staining, ${ }^{15}$ which can lead to misclassification of HER2 status.

FISH is viewed as the "gold standard" technique in identifying patients who would benefit from trastuzumab but it is an expensive test and requires fluorescence microscope. ${ }^{17}$ IHC is a semi quantitative assay and has many limitations, both technical and interpretative, which have been found to impact on the reproducibility and accuracy of the result. ${ }^{16}$ CISH is a modification of FISH for detection of HER-2 gene amplification. ${ }^{18}$ It allows simultaneous evaluation of gene copy numbers, tumor cells, and detailed surrounding tissue morphology on the same histology slide. ${ }^{18}$ CISH testing is sensitive and specific in detecting HER-2/neu gene amplification. It is also practical, cost effective and convenient to perform as it does not require special equipment like fluorescence microscope and much experience in interpreting results. ${ }^{19}$ Direct evaluation of gene amplification using CISH assay is a reliable method for routine diagnostic evaluation of HER2/neu status in breast cancer patients, especially in specimens showing 2+ IHCscore. ${ }^{20}$

There are two methods of CISH assay: Standard CISH, which uses an HER-2 probe only and dual-color CISH (dc-CISH), which 
uses a HER-2 probe and a CEN17 (chromosome 17 centromere) probe. Inclusion of CEN17 probe in dual-color CISH allows calculating HER-2/CEN17 ratio which is able to exclude chromosome 17 polysomy. ${ }^{21}$

In dual color CISH, HER-2 CISH stained slides interpreted with bright field microscope at 40x objectives are categorized as amplified and non amplified. The calculated HER-2/CEN-17 ratio 2 or more is indicative of gene amplification, and $<2$ indicates non-amplification. The HER2/CEN-17 ratio calculation is based on the enumeration of 20 nuclei from the invasive tumor area. $^{22}$

In practice, patients with IHC $3+$ tumours are eligible for getting trastuzumab, whereas those with IHC 0/1+ tumours are not. ${ }^{23} \mathrm{IHC} 2+$ group is considered not as positive but as a borderline/equivocal group. A subset of this group doesn't show any response to trastuzumab, whereas all those having gene amplification respond with trastuzumab favorably. ${ }^{24}$

Currently, the recommended assays are a combination of IHC and FISH; especially an IHC score of 2+ (equivocal case) is referred to FISH for a definitive treatment decision. ${ }^{25}$ As FISH is an expensive test, CISH provides an attractive alternative to FISH and can be used as a primary test to detect HER-2 status or to retest IHC score $2+$ (equivocal). ${ }^{21}$ Patients whose tumours scored 2+ with IHC would benefit from CISH assay for HER2/ neu status more accurately and help the clinicians/ oncologists to select the right patient for trastuzumab therapy. ${ }^{17}$ So this equivocal group should be retested with CISH because a positive CISH score indicates eligibility for anti HER-2 antibody trastuzumabtherapy. ${ }^{23}$

The aim of this study was to assess HER-2 expression accurately in equivocal immunohistochemistry (2+) invasive breast cancer cases by Chromogenic in situ hybridisation (CISH) and to associate the findings of CISH assay with the histologic prognostic and predictive factors (eg: tumor size, regional lymph node metastases, tumor grade and type).

\section{Materials and Methods}

It was an observational experimental study. It was done in the Department of Pathology, BSMMU, from July 2014 to June 2015. 20 archival paraffin tissue blocks of invasive breast carcinoma cases with equivocal (2+) immunohistochemistry scores for HER-2/neu were included in this study. Relevant information and data including patient's age, sex, tumor size and lymph node status were collected from hospital records in a prescribed proforma for each case. One positive control (score $3+$ ) and a negative control (score-0) for HER-2/neu were also included in this study at the first CISH assay run to observe whether the procedure technique was in the proper way or not. Actually, surrounding normal cells within the sample were allowed for an internal control of the staining run.

For histopathological and immunohistochemical reassessment haematoxylin and eosin $(\mathrm{H} \& \mathrm{E})$ slides and IHC slides with score 2+ for HER-2/neu were collected (from January 2013 to April 2015) from the immunohistochemistry laboratory, Department of Pathology, BSMMU. The slides were subsequently reviewed and the cases were selected for CISH assay. Immunohistochemical assessment of HER2/neu expression was performed according to the American Society of Clinical Oncology (ASCO) guidelines : Score 0 (negative): no staining or membrane staining in $<10 \%$ of tumor cells, Score 1+ (negative): a faint or barely perceptible membrane staining detected in more than $10 \%$ of tumor cells, Score 2+ (weakly positive or borderline): weak to moderate complete membrane staining seen in more than $10 \%$ of tumor cells, Score 3+ (strongly positive): strong complete membrane staining seen in more than $30 \%$ of tumor cells.

HER-2 gene was detected by hybridisation of denatured chromosomal DNA with labelled DNA probe on formalin fixed, paraffin embedded tissue sections. Chromogenic in situ hybridisation (CISH) was performed using Dako's HER2 CISH pharmDX ${ }^{\mathrm{TM}}$ Kit -SK109 which contained mixture of two labelled DNA probes: Texas Red-labeled HER-2 probe (for a red signal), and FITC-labeled chromosome 17 centromere probe (CEN17) for a blue signal). Four to five micrometer thick sections were cut 
from archival paraffin blocks and mounted on silane-coated slides. Slides were air dried and baked overnight at $56^{\circ} \mathrm{c}$, deparaffinized in xylene followed by immersion in ethanol ( $96 \%$ and $70 \%$ ) for $2 \mathrm{~min}$. Sections were heated in pretreatment solution for 10 minutes at $95^{\circ} \mathrm{C}$. After 15 minutes at room temperature and washing with wash buffer solution, the slides were incubated with $250 \mu \mathrm{L}$ of enzyme pepsin for 2 minutes at $37^{\circ} \mathrm{C}$, dehydrated with graded ethanols, and air dried. Ten $\mu \mathrm{L}$ of labelled HER 2 and CEN17 probe mix was applied to the slides, covered with coverslips and sealed with cover sealant. Denaturation was done at $85^{\circ} \mathrm{C}$ for 5 minutes followed by hybridisation for 20 hours at $45^{\circ} \mathrm{C}$ in Hybridizer. The slides were kept in stringent wash buffer for 10 minutes at $65^{\circ} \mathrm{C}$, washed with Wash buffer-1 and Wash buffer-2 solution respectively. After peroxidase blocking slides were incubated with $400 \mu$ LCISH antibody mix for 30 minutes in a humid chamber. The slides were then washed with Wash buffer-2 solution followed by application of red and blue chromogen. Finally, sections were lightly counter stained with haematoxylin and covered with CISH mounting medium.

The number of HER-2/neu and CEN 17 signals per cellular nucleus was recorded under 40x and 100x objectives using a conventional microscope (Olympus CX-22). HER-2/neu amplification typically appears as large peroxidase positive intranuclear gene copy clusters. Scan was done from left to right beginning from upper left corner of the selected area. Red and blue signals were counted according to signal counting guide by manufacturer's (DAKO) instructions. HER-2 CISH stained slides interpreted with bright field microscope at 40x and 100x objectives were categorized as amplified and non amplified. The calculated HER-2/CEN-17 ratio 2 or more was considered indicative of gene amplification, and $<2$ as non-amplification. The HER-2/CEN-17 ratio calculation was based on the enumeration of 20 cellular nuclei from the representative invasive tumor area. In case the ratio was found borderline (1.8-2.2), 20 additional nuclei were counted and the ratio was recalculated from total score of 40 nuclei.
Statistical analyses were carried out using the Statistical Package for Social Sciences version 15.0 for Windows (SPSS Inc., Chicago, Illinois, USA). The results were depicted in tables, figures and diagrams. The mean values were calculated for continuous variables. The quantitative observations were indicated by frequencies and percentages. Chi-Square test was used to analyze the categorical variables, shown with cross tabulation. ANOVA test was used to analyze the continuous variables, shown with mean and standard deviation. $\mathrm{p}$ values $<0.05$ was considered as statistically significant.

\section{Results}

Out of the total 20 study cases, 8 (40\%) were belonged to the age group 41-50 years. The next common age groups were, chronologically $31-40$ (20\%), 51-60 (20\%) and $\leq 30(15 \%)$. The mean age was $44.4 \pm 11.9$ years with range from 22 to 70 years. Among the study population, 19 (95\%) were female, only one $(5 \%)$ was male. Nineteen cases $(95 \%)$ were invasive ductal carcinoma (NOS) while one case was mucinous carcinoma.

Regarding tumor size,11(55\%) of the cases were in between $2.1-5.0 \mathrm{~cm}, 7(35 \%)$ cases were $>5 \mathrm{~cm}$ and only one (5\%) case was $2 \mathrm{~cm}$. Tumour size was not mentioned in one case. The mean size was $4.6 \pm 2.3 \mathrm{~cm}$ with range from 2 to $10 \mathrm{~cm}$. Histologically, fifteen $(75 \%)$ cases were grade II tumors followed by $3(15 \%)$ cases grade I and one $(5 \%)$ case grade III tumour. One $(5 \%)$ case, the mucinous carcinoma was not graded. Tumour grading were done by Nottingham Histologic score. Regional lymph node metastasis was present in $15(75 \%)$ cases. Metastasis was absent in $3(15 \%)$ cases. Two $(10 \%)$ cases were lumpectomy samples without lymph node sampling.

Of the total cases, CISH assay showed amplification of the HER-2 neu gene in 06(30\%) cases. Majority $12(60 \%)$ were non amplified. In two cases the results were unsatisfactory (red and blue signals were absent) for interpretation.

Among the study population, mean age was to be found 41.0 \pm 9.6 years in amplified and $45.1 \pm 13.1$ years in non amplified group. The 
only one male case was in the non amplified group. The mean difference was not statistically significant $\quad(\mathrm{p}>0.05)$ among three groups (table I).

The mean tumor size was found $4.5 \pm 1.8 \mathrm{~cm}$ in amplified, $4.5 \pm 2.1 \mathrm{~cm}$ in non amplified and $6.3 \pm 5.3 \mathrm{~cm}$ in unsatisfactory groups. The mean difference was not statistically significant (p>0.05) among three groups. Majority of the cases, 5(83.3\%) and 8(80.0\%) in amplified and non amplified groups respectively, showed presence of lymph node metastasis. No significant relation was found between lymphnode metastasis, tumor grade and HER2/neu amplification (table II).

Table I: Association of the baseline characteristics with CISH $(n=20)$

\begin{tabular}{|c|c|c|c|c|c|c|c|}
\hline \multirow{3}{*}{$\begin{array}{c}\text { Baseline } \\
\text { characteristics }\end{array}$} & \multicolumn{6}{|c|}{ CISH } & \multirow{3}{*}{$\underset{\text { value }}{\mathbf{p}}$} \\
\hline & \multicolumn{2}{|c|}{$\begin{array}{l}\text { Amplified } \\
(n=6)\end{array}$} & \multicolumn{2}{|c|}{$\begin{array}{l}\text { Non amplified } \\
\quad(n=12)\end{array}$} & \multicolumn{2}{|c|}{$\begin{array}{l}\text { Unsatisfactory } \\
\qquad(\mathrm{n}=2)\end{array}$} & \\
\hline & $\mathbf{n}$ & $\%$ & $\mathbf{n}$ & $\%$ & $\mathbf{n}$ & $\%$ & \\
\hline \multicolumn{8}{|l|}{ Age (in year) } \\
\hline$\leq 30$ & 01 & 16.7 & 02 & 16.7 & 00 & 0 & \\
\hline $31-40$ & 01 & 16.7 & 02 & 16.7 & 01 & 50 & \\
\hline $41-50$ & 04 & 66.7 & 04 & 33.3 & 00 & 0 & \\
\hline $51-60$ & 00 & 0 & 03 & 25 & 01 & 50 & \\
\hline$>60$ & 00 & 0 & 01 & 8.3 & 00 & 0 & \\
\hline Mean \pm SD & \multicolumn{2}{|c|}{$41.0 \pm 9.6$} & \multicolumn{2}{|c|}{$45.1 \pm 13.1$} & \multicolumn{2}{|c|}{$50.0 \pm 14.1$} & \\
\hline $\begin{array}{l}\text { Range } \\
(\min , \max )\end{array}$ & \multirow{2}{*}{\multicolumn{2}{|c|}{23,50}} & \multicolumn{2}{|c|}{22,70} & \multicolumn{2}{|c|}{40,60} & 0.638 \\
\hline \multicolumn{6}{|l|}{ Sex } & & \\
\hline Male & 00 & 0 & 01 & 8.3 & 00 & 0 & \multirow{2}{*}{0.704} \\
\hline Female & 06 & 100 & 11 & 91.7 & 02 & 100 & \\
\hline
\end{tabular}

Table II: Association of tumor size, tumor grade and lymphnode metastasis with CISH $(n=20)$

\begin{tabular}{|c|c|c|c|c|c|c|c|}
\hline \multirow[t]{2}{*}{$\begin{array}{l}\text { Tumor } \\
\text { status }\end{array}$} & \multicolumn{2}{|c|}{$\underset{(n=6)}{\text { Amplified }}$} & \multicolumn{2}{|c|}{$\begin{array}{c}\text { CISH } \\
\text { Non amplified } \\
(n=12)\end{array}$} & \multicolumn{2}{|c|}{$\begin{array}{c}\text { Unsatisfactory } \\
\qquad(n=2)\end{array}$} & \multirow[t]{2}{*}{ p value } \\
\hline & $\mathbf{n}$ & $\%$ & $\mathbf{n}$ & $\%$ & $\mathbf{n}$ & $\%$ & \\
\hline \multicolumn{8}{|l|}{$\begin{array}{l}\text { Tumor size } \\
(\mathrm{cm})\end{array}$} \\
\hline$\leq 2$ & 1 & 16.7 & 0 & 0.0 & 0 & 0.0 & \\
\hline $2.1-5.0$ & 3 & 50.0 & 7 & 58.4 & 1 & 50.0 & \\
\hline$>5.0$ & 2 & 33.3 & 4 & 33.3 & 1 & 50.0 & \\
\hline $\begin{array}{l}\text { Not } \\
\text { mentioned }\end{array}$ & 0 & 0.0 & 1 & 8.3 & 0 & 0.0 & \\
\hline Mean \pm SD & 4.5 & \pm 1.8 & 4.5 & \pm 2.1 & 6.3 & \pm 5.3 & \\
\hline $\begin{array}{l}\text { Range } \\
(\min , \max )\end{array}$ & 2.0 & ,7.0 & 2.5 & , 8.0 & 2.5 &, 10.0 & $0.595^{\mathrm{ns}}$ \\
\hline \multicolumn{8}{|l|}{$\begin{array}{l}\text { Tumor } \\
\text { grade }\end{array}$} \\
\hline I & 1 & 16.7 & 2 & 16.7 & 0 & 0.0 & \\
\hline II & 5 & 83.3 & 8 & 66.7 & 2 & 100.0 & $0.919^{\mathrm{ns}}$ \\
\hline III & 0 & 0.0 & 1 & 8.3 & 0 & 0.0 & \\
\hline $\begin{array}{l}\text { Not } \\
\text { mentioned }\end{array}$ & 0 & 0.0 & 1 & 8.3 & 0 & 0.0 & \\
\hline $\begin{array}{l}\text { Lymph } \\
\text { node } \\
\text { metastasis }\end{array}$ & & & & & & & \\
\hline Present & 05 & 83.3 & 08 & 80.0 & - & - & $0.696^{\mathrm{ns}}$ \\
\hline Absent & 01 & 16.7 & 02 & 20.0 & - & - & \\
\hline
\end{tabular}

Sensitivity and accuracy of IHC were estimated considering CISH as the gold standard, Six cases were positive out of 18 cases, so detection of true positive cases from equivocal IHC cases is $33.33 \%$ (table III)

Table III: Association between tumor size with CISH $(\mathrm{n}=20)$

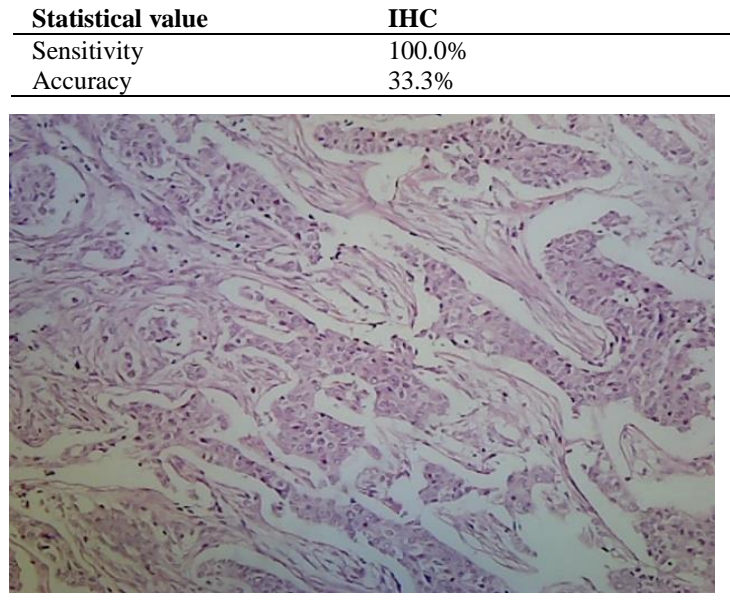

Figure 1a: Photomicrograph shows invasive ductal carcinoma. (Case-2), H \& E x 100

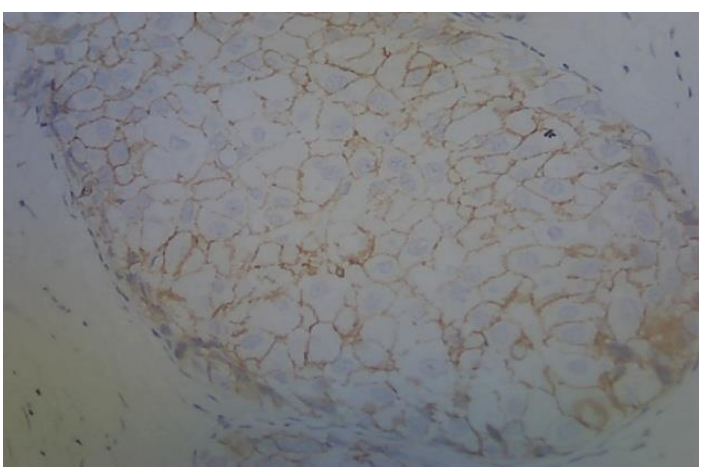

Figure 1b: HER-2/neuimmunostain (score2+), (Case-2)x 400

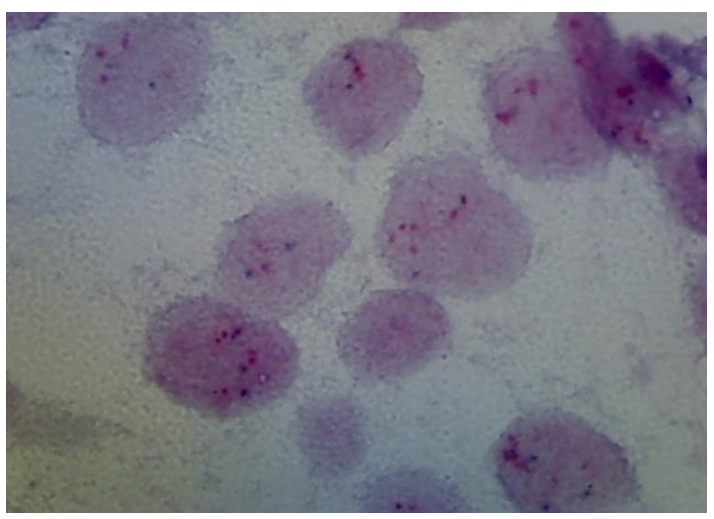

Figure 1c: HER-2/neu gene status (red dot) and CEN- 17 (blue dot), (Case-2), CISH x 1000 


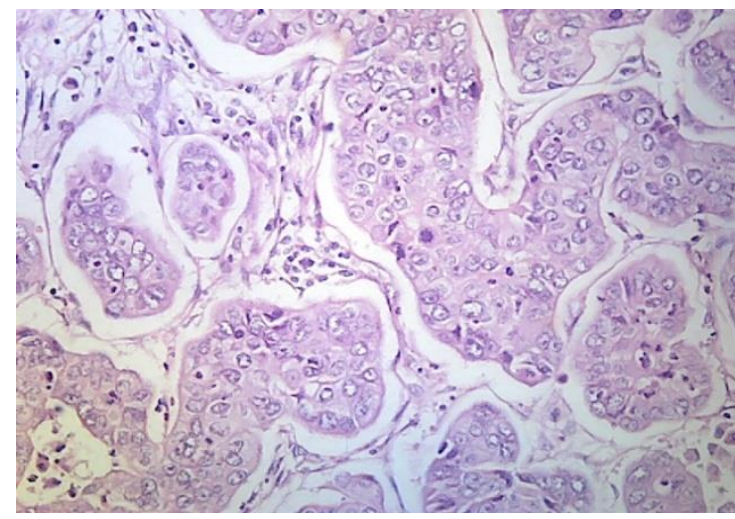

Figure 2a: Photomicrograph shows invasive ductal carcinoma. (Case-1), H \& E x 200

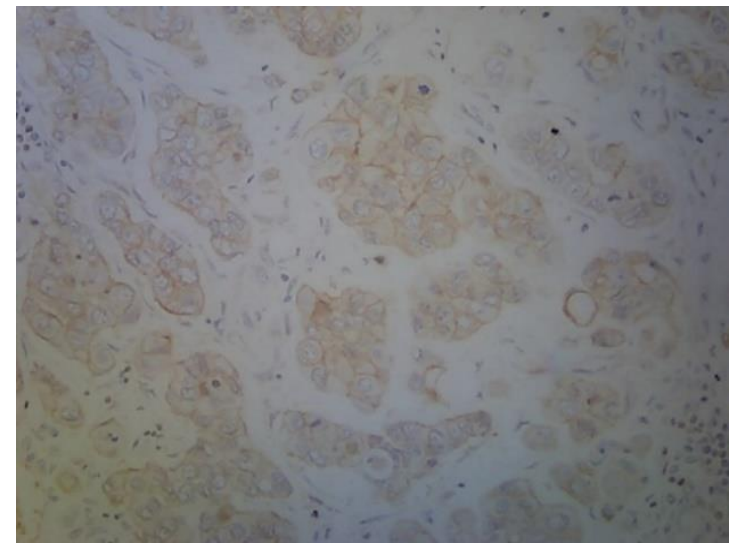

Figure 2b: Photomicrograph shows HER-2 (2+) immunostaining. (Case-1), HER-2 IHC x 200

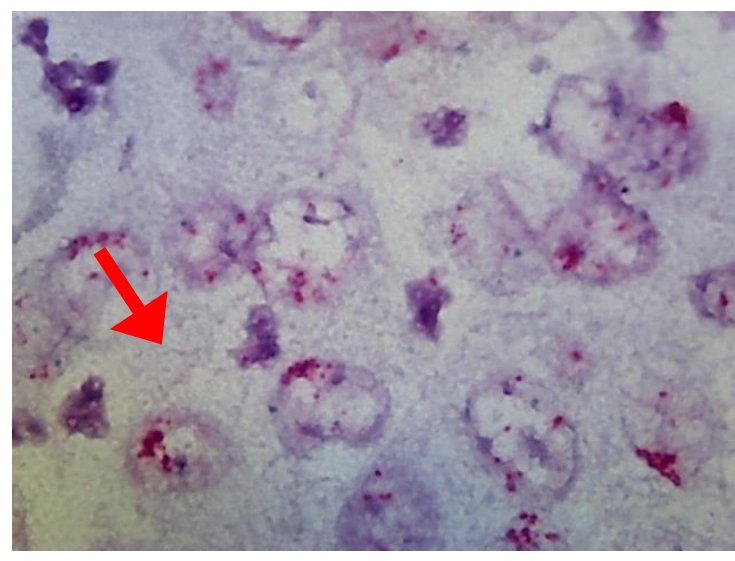

Figure 2c: Photomicrograph shows amplification of HER-2/neu gene marked by arrow (Case-1), CISH x 1000

\section{Discussion}

Usually, HER2/neu testing algorithm starts with immunohistochemical analysis. Whether a patient is eligible for anti-HER-2 therapy depends on clear-cut HER2/neu status determined by immunohistochemical analysis. Cases with equivocal (2+) immunohisto chemical results should be retested and confirmed with CISH. ${ }^{17}$

So far no such study has been done in Bangladesh. In this study, a total of twenty (20) archival paraffin tissue blocks were included. Obviously, the limitation of this study was that the sample size was small. But still the study reflected a little on the clinicopathological parameters. All the CISH amplified cases belonged to invasive ductal carcinoma group and all patients were females. No significant correlation was observed between the histologic type of breast carcinoma and HER-2/neu gene amplification by CISH. Similar findings were reported in other study. ${ }^{17}$ As regards, clinicopathologic correlation, no statistically significant association existed between HER$2 /$ neu gene status and age, tumor grade or lymph node metastasis. This was also reported by other investigators. ${ }^{26}$ No significant association between the age and HER2 gene amplification by FISH was also seen by Panjwani. ${ }^{27}$ No significant association between tumour size and HER-2/neu status was found by previous study. ${ }^{28}$ Similarly, this study failed to establilish significant association between tumor size and HER-2/neu status.

Several studies showed nearly similar frequency of HER-2/neu gene amplification, that found in present study. ${ }^{17,23,29}$ But others reported significant higher rates. ${ }^{19,30}$ Possible explanations for these results could be attributed to variation in time of fixation, processing condition and use of different manufacturers kits. In this current study CISH assay showed amplification of the HER-2 neu gene in $30 \%$ of cases. Majority $(60 \%)$ was non amplified. In two cases (10\%) the results were unsatisfactory for interpretation, may be due to improper tissue processing, or excess paraffin retention in tissue. Repeat CISH assay could not be done in these two cases, due to limited amount of HER-2 probe. Six cases were positive out of 18 cases, so detection of true positive cases from equivocal IHC cases is $33.33 \%$. This is comparable to other studies that showed nearly similar frequency of HER- 
2/neu amplification by CISH assay. 17,23,29 Such cases with IHC score $2+$ and with negative gene amplification by CISH are considered as false positive by IHC. There are some factors leading to false IHC test results, including variability in tissue fixation and processing, variable sensitivity and specificity of commercially available antibodies, and differences in scoring criteria with considerable interobserver variability in interpretation of results. ${ }^{15}$ Therefore the combined use of IHC and CISH may be useful for the better selection of patients with breast cancer that will benefit from therapy with Trastuzumab.

\section{Conclusion}

HER-2 / neu status is the one of the most important prognostic and predictive factor, a target for treatment with anti HER-2 antibody trastuzumab (Herceptin). Detection of HER-2/ neu status by IHC may some times be difficult and inaccurate, specially in IHC score 2+ cases. This study was undertaken to assess HER-2 expression accurately by CISH assay in equivocal 2+ HER-2 invasive breast cancer. Based on the present findings, CISH can be considered a useful, simple and reproducible method for detecting HER-2/ neu gene amplification in cases with borderline (2+) immunohistochemistry score, and such patients would be benefitted from Trastuzumab therapy

Acknowledgements: The authors would like to acknowledge the University Grant Committee for providing grant to conduct this study.

\section{References}

1. Ferlay J., Soerjomataram I; Dikshit R; Eser, S; Mathers C; Rebelo $\mathrm{M}$ et al. Cancer incidence and mortality worldwide: sources, methods and major patterns in GLOBOCAN 2012. Int J Cancer. 2015; 136: E359-86.

2. Chin K, De Vries S, Fridlyand J, Spellman P, Roydasgupta R, Kuo W.L. et al. Genomic and transcriptional aberrations linked to breast cancer pathophysiologies. Cancer Cell. 2006, 10: 529541.

3. Cianfrocca M, Goldstein LJ, Prognostic and Predictive Factors in Early-Stage Breast Cancer. Oncologist. 2004; 9: 606-16.

4. Murthy SS, Sandhya DG, Ahmed F, Goud KI, Dayal M, Suseela K et al. Assessment of HER2/Neu status by fluorescence in situ hybridisation in immunohistochemistry-equivocal cases of invasive ductal carcinoma and aberrant signal patterns: a study at a tertiary cancer center. Indian J Pathol Microbiol. 2011; 54: 532-8.

5. Akiyama C, Sudo H, Ogawara K, Yamamoto T. The product of the human c-erbB-2 gene: a 185kilodalton glycoprotein with tyrosine kinase activity. Science. 1986; 232: 1644-1646.

6. Reese DM, Slamon DJ. Her-2/neu signal transduction in human breast cancer and ovarian cancer. Stem cells 1997; 15.

7. Burstein HJ. The distinctive nature of HER2positive breast cancers. N Engl J Med. 2005; 353: 1652-4.

8. Pauletti G, Dandekar S, Rong H, Ramos L, Peng $\mathrm{H}$, Seshadri R, Methods for tissue-based detection of the HER-2/neu alteration in human breast cancer: a direct comparison of fluorescence in situ hybridisation and immunohistochemistry. J Clin Oncol 2000; 18: 3651-64.

9. Mass RD, Press MF, Anderson S, Cobleign MA, Vogel CL, Dybdal N et al. Evaluation of clinical outcomes according to HER 2 detection by fluorescence in situ hybridisation in women with metastatic breast cancer treated with Trastuzumab. Clinical Breast Cancer. 2005; 6: 240-246.

10. Lin A, Rugo HS. The role of trastuzumab in early stage breast cancer: current data and treatment recommendations. Curr Treat Options Oncol. 2007; 8: 47-60.

11. Slamon D, Eierman W, Robert N, PienkowskiT, Martin M, Pawlicki M et al. Phase III randomized trial comparing doxorubicin and cyclophos phamide followed by docetaxel $(\mathrm{AC} \rightarrow \mathrm{T})$ with doxorubicin and cyclophosphamide followed by docetaxel and trastuzumab ( $\mathrm{AC} \rightarrow \mathrm{TH})$ with docetaxel, carboplatin and trastuzumab (TCH) in HER2positive early breast cancer patients: BCIRG 006 study. Breast Can Res Treat. 2005; 94: 5S.

12. Dean-Colomb W, Esteva FJ, HER2-positive breast cancer: Herceptin and beyond. Eur J Cancer. 2008; 44: 2806-12.

13. Tanner M, Gancberg D, Larsimont D, Rouas G, Piccart MJ, Isola $\mathrm{J}$ et al. Chromogenic in situ hybridisation: a practical alternative for fluorescence in situ hybridisation to detect HER$2 /$ neu oncogene amplification in archival breast cancer samples. Am J Pathol. 2000; 157: 1467-1472.

14. Ross JS, Fletcher JA, Linette GP, Stec J, Clark E, Ayers, M et al. 2003. HER-2/neu gene and protein in breast cancer, Biomarker and target of therapy. Oncologist. 2003; 8: 307-25.

15. Jacobs TW, Gown AM, Yaziji H, Barnes, MJ, Schnitt SJ. HER-2/neu protein expression in breast cancer evaluated by immunohistochemistry. A 
study of interlaboratory agreement. Am J Clin Pathol. 2000; 113: 251-8.

16. Press MF, Hung G, Godolphin G, Slamon D.J. Sensitivity of Her-2/neuantibodies in archival tissue samples: potential source of error in immunohistochemical studies of oncogene expression. Cancer Res. 1994;54: 2771-2777.

17. Asif M, Khadim MT, Mushtaq S., MamoonN, Akhtar F, Ali Z. Determination of HER-2/neuby Chromogenic in Situ Hybridisation on Borderline (2+) Immunohistochemistry Cases in Carcinoma Breast. Asian Pacific J Cancer Prev. 2011;12: 211-214.

18. Isola J, Tanner M, Forsyth A, Cooke TG, Watters $\mathrm{AD}$, Bartlett JM. Interlaboratory comparison of HER-2 oncogene amplification as detected by chromogenic and fluorescence in situ hybridisation. Clin Cancer Res. 2004; 10: 4793-8.

19. Vocaturo A, Novelli F, Benevolo M, Piperno G, Marandino F, Cianciulli, AM, Roberta Merola R. et al. Chromogenic In Situ Hybridisation to Detect HER-2/neuGene Amplification in Histological and Thin PrepR-Processed Breast Cancer Fine-Needle Aspirates: A Sensitive and Practical Method in the Trastuzumab Era. The Oncologist. 2006;11: 878-886.

20. Di Palma S, Collins N, Faulkes C. Chromogenic in situ hybridisation (CISH) should be an accepted method in the routine diagnostic evaluation of HER-2/neustatus in breast cancer. J Clin Pathol. 2007; 60: 1067-8.

21. Penault-Llorca F, Bilous M, Dowsett M, Hanna W., OsamuraRY, Rüschoff J. et al. Emerging Technologies for Assessing HER2Amplification. Am J Clin Pathol. 2009; 132: 539-548.

22. Mollerup J, Henriksen U, Müller S, Schonau A. Dual color chromogenic in situhybridisation for determination of HER2 status in breast cancer: a large comparative study to current state of the art fluorescence in situ hybridisation. BMC Clinical Pathology. 2012; 12: 1-7.

23. Van de Vijver M, Bilous M, Hanna W, Hofmann $\mathrm{M}$, Kristel $\mathrm{P}$ et al. Chromogenic in situ hybridisation for the assessment of HER2 status in breast cancer: an international validation ring study. Breast Cancer Research. 2007; 9: R68.

24. Madrid MA, Lo RW. Chromogenic in situ hybridisation (CISH): a novel alternative in screening archival breast cancer tissue samples for HER-2/neustatus. Breast Cancer Research. 2004; 6: R593- R600.

25. Goud KI, Dayakar S, Vijayalaxmi K, Babu SJ, Reddy VAP. Evaluation of HER-2/neustatus in breast cancer specimens using immunohistochemistry (IHC) \& fluorescence insitu hybridisation (FISH) assay. Indian J Med Res. 2012; 135: 312-317.

26. Mostafa NAE, Eissa SS, Belal DM, Shoman SH. Assessment of Her-2/neu gene amplification status in breast carcinoma with equivocal $2+$ Her2/neu immunostaining. Journal of the Egyptian National Cancer. 2011; 23: 41-46.

27. Panjwani P, Epari S, KarpateA., Shirsat H, Rajsekharan P, BasakR et al. Assessment of HER$2 /$ neu status in breast cancer using fluorescence in situhybridisation \& immunohistochemistry: Experience of a tertiary cancer referral centre in India. Indian J Med Res. 2010; 132: 287-294.

28. DandachiN, Dietze O, Hauser-Kronberger C. Evaluation of the Clinical Significance of HER2 Amplification by Chromogenic. In Situ Hybridisation in Patients with Primary Breast Cancer. Anticancer Research. 2004; 24: 2401-2406.

29. Peiro G, Aranda FI, Adrover E, Niveiro, M., Alenda C, Paya A et al. Analysis of HER-2/neuby chromogenic in situ hybridisation an $\mathrm{d}$ Immunohistochemistry in lymph node negative breast carcinoma: prognostic relevance. Hum Pathol. 2007; 38: 26-34.

30. Hauser-Kronberger C, Dandachi N. Comparison of chromogenic in situ hybridisation with other methodologies for HER2 status assesment in breast cancer. Journal of Molecular Histology. 2004; 35: 647-653. 